\title{
Theoretical study on the reaction mechanism of formation of
}

\section{3,5-diacetyl-1,4-dihydrolutidine}

\author{
Hiroyuki TERAMAE ${ }^{1}$, Yasuko Y. MARUO²
}

${ }^{1}$ Department of Chemistry, Josai University, 1-1 Kyakidai, Sakado, Saitama 3500295, Japan

2 NTT Energy \& Environmental Laboratories, 3-1 Wakamiya, Morinosato, Atsugi, Kanagawa 2430198, Japan

\section{Abstract}

We have studied the reaction path of the formation of 3,5-diacetyl-1,4-dihydrolutidine (DL1), 3,5-dibenzoyl-1,4-dihydro-2,6-dimethylpyridine, and 2,6-dibenzoyl-1,4-dihydro-3,5-dimethylpyridine with the ab initio molecular orbital method at $\mathrm{HF} / 3-21 \mathrm{G}$ and $\mathrm{HF} / 6-31 \mathrm{G}(\mathrm{d}, \mathrm{p})$ levels. For DL1, we also calculated at MP2/6-31G(d,p) level. The barrier heights of $\mathrm{H}_{2} \mathrm{O}$ elimination elementary reactions are ca. $50-60 \mathrm{kcal} / \mathrm{mol}$ and quite high in the gas phase, however, this is well agreed with the experimental results that the reaction proceeds in aqueous solutions.

1. Introduction

The explicit detection of the concentration of the formaldehyde in the air becomes 
more and more important in these years, because the formaldehyde could be a reason of the sick building syndrome, i.e., sensory irritation of the eyes, nose, throat atopic dermatitis, as well as the carcinogenicity and mutagenicity The formaldehyde are contained in the building material, wallpaper, paint, domestic houseware, etc. [1-5]. The World Health Organization has set a standard for safe exposure of $0.08 \mathrm{ppm}$ averaged over 30 minutes [6].

The measurement of the formaldehyde is based on the acetyl acetone method (Nash Reagent) in the aqueous solution as shown in Fig.1 [7]. The method utilizes the reaction of two acetyl acetone molecules, ammonium ion, and formaldehyde molecule yielding the lutidine derivative. Note that there is a certain substituent effect of the reactants. The lutidine derivative from pentane-2,4-dione $\left(\mathrm{R}_{1}, \mathrm{R}_{2}=\mathrm{CH}_{3}\right)$ and the 1-phenyl-1,3-butanedione $\left(\mathrm{R}_{1}=\mathrm{CH}_{3}, \mathrm{R}_{2}=\mathrm{Ph}\right)$ are easily obtained, however, the lutidine derivative from 1,3-diphenyl-1,3-propanedione $\left(\mathrm{R}_{1}=\mathrm{Ph}, \mathrm{R}_{2}=\mathrm{Ph}\right)$ is not able to obtain within this scheme.

It is important to point out that the acetyl acetone method needs to absorb the formaldehyde in aqueous solution, and measures the formaldehyde only in the aqueous solution. For the detection of the formaldehyde in the gas phase, it is necessary to absorb the gas containing the formaldehyde in the water to make an aqueous solution. 
Heating is necessary because the reaction is slow. Note that in order to avoid the heating and the substituent effect, the synthesis of the reaction intermediate compound, FLUORAL-P (4-amino-3-penten-2-one) is necessary [10]. Suzuki et al. recently reported the synthesis of $\mathrm{KD}-\mathrm{XA} 01$ and $\mathrm{KD}-\mathrm{XA} 02$, which are the compounds analogous to FLUORAL-P from 1,3-diphenyl-1,3-propanedione and 1,3-diphenyl-1,3-propanedione [11]. Starting from FLUORAL-P, KD-XA01, and KD-XA-02, we can also obtain the lutidine derivatives without heating.

Finally, the lutidine derivative is identified by the color of solution $(407 \mathrm{~nm}, 414 \mathrm{~nm}$, and $424 \mathrm{~nm}$ for the lutidine derivatives from pentane-2,4-dione, 1-phenyl-1,3-butanedione, and 1,3-diphenyl-1,3-propanedione, respectively). These procedures are not easy to apply on the detection of the formaldehyde in the gas phase, as mentioned above. The methods nowadays are all based on the Nash reagent, and finding the new method to measure the concentration of the formaldehyde in gas phase is significantly important.

The lutidine derivatives in the Fig.1 are, 3,5-diacetyl-1,4-dihydro-2,6-dimethylpyridine （3,5-diacetyl-1,4-dihydrolutidine） (here after referred as DL1), 3,5-dibenzoyl-1,4-dihydro-2,6-dimethylpyridine (here after referred as DL2) , 3,5-dibenzoyl-1,4-dihydro-2,6-diphenylpyridine (here after referred as 
DL3), where the only IUPAC names are given for the methyl phenyl, and the diphenyl substitutions.

Very recently, Maruo and co-workers [8] found that $\beta$ diketones (pentane-2,4-dione, 1-phenyl-1,3-butanedione, or 1,3-diphenyl-1,3-propanedione) and ammonium salts in porous glass can be used for a measurement of formaldehyde in the gas phase. These products have absorption peaks around $410 \mathrm{~nm}$, which is used for the detection of formaldehyde by the acetyl acetone method in aqueous solution.

There are several interesting features of the lutidine derivative in porous glass. In aqueous solution, the absorbance of the lutidine derivatives (DL1 and DL2) decreases after certain standing time, however, in porous glass, absorbance of DL2 does not decrease. 1,3-diphenyl-1,3-propanedione does not react in the aqueous solution but does in the porous glass to yield DL3 and the absorption intensity decreases when increasing the amount of HCHO. Reasons for these features of lutidine compounds are still remained mystery.

In our previous work, the ground and excited states of DL1 are calculated with the ab initio molecular orbital method at HF/3-21G, CIS/3-21G, B3LYP/6-31G(d, p), and TD B3LYP/6-31G(d, p) levels. We tried to explain the difference of the environment (in aqueous solution or in porous glass), however, the substituent effects was remained 
mystery.

In this article, as a first step of figuring out the substituent effects, we perform ab initio molecular orbital calculations to obtain the reaction path from pentane-2,4-dione to DL1. We also perform the reaction path calculations from 1-phenyl-1,3-butanedione $\left(\mathrm{R}_{1}=\mathrm{CH}_{3}, \mathrm{R}_{2}=\mathrm{Ph}\right)$ to $\mathrm{DL} 2$. We examined the calculations from 1-phenyl-1,3-butanedione to 2,6-dibenzoyl-1,4-dihydro-3,5-dimethylpyridine $\left(\mathrm{R}_{1}=\mathrm{Ph}, \quad \mathrm{R}_{2}=\mathrm{CH}_{3}\right)$ for just a comparison, which is not available experimentally.

\section{Method of Calculations}

The reaction path calculations are performed at HF/3-21G and HF/6-31G(d, p) levels for the reaction starting from pentane-2,4-dione to DL1, from 1-phenyl-1,3-butanedione to DL2, and from 1-phenyl-1,3-butanedione to 2,6-dibenzoyl-1,4-dihydro-3,5-dimethylpyridine. We did not calculate the reaction path from 1,3-diphenyl-1,3-propanedione to DL3 in the present work.

The reaction path calculations from pentane-2,4-dione are also examined at MP2/6-31G(d,p) level. The vibrational frequency calculations are performed to confirm the equilibrium and transition state structures, and to calculate the zero point energy correction to the total energy (ZPC). All the calculations are carried out using 
Gaussian09 program package [9].

\section{Results and Discussion}

Figure 2 shows a possible reaction path from acetyl acetone to lutidine derivative.

The acetyl acetone 1 gets proton and forms 2.2 then reacts with ammonia and forms 3 .

From 3, a proton is eliminated and forms 4. A water molecule is eliminated from 4 and forms a FLUORAL-P 5. A resonance structure 5' of FLUORAL-P reacts with a formaldehyde molecule and forms 6.6 gets a proton and forms 7. A water molecule is eliminated from 7 and forms 8. 8 again reacts with a resonance structure 5 ' of FLUORAL-P molecule 5 and forms 9. A proton is eliminated from 9 and forms 10 . A ammonia molecule is eliminated from 10, and forms a lutidine derivative 11.

Along with the reaction path of Fig. 2, we performed ab initio molecular orbital calculations. At the present time, the full reaction path is only obtained at the HF/3-21G level starting from pentane-2,4-dione whose energy diagram after the zero point energies correction (ZPC) is shown in Fig.3. Figure 4 shows the schematic views of the optimized and the transition state structures corresponding to Fig. 3. Note that the energies are approximate because the Hartree-Fock energies are not size-consistent.

In the present model reaction system, a proton is added or eliminated by itself. 
However, the Broensted acids which give a proton to acetyl acetone should exist. As an example, we considered a direct reaction path from 1 to 3 by addition of $\mathrm{NH}_{4}{ }^{+}$and the path from 3 to 5 by elimination of $\mathrm{H}_{3} \mathrm{O}^{+}$. We could easily obtain the transition state of addition of $\mathrm{NH}_{4}^{+}$, however, we could not obtain the transition state of elimination of $\mathrm{H}_{3} \mathrm{O}^{+}$. All that we could obtain is a transition state of the proton transfer from $\mathrm{H}_{3} \mathrm{O}^{+}$to 5. The $\mathrm{HF} / 3-21 \mathrm{G}$ energy of $\mathbf{5}+\mathrm{H}_{3} \mathrm{O}^{+}$is -397.984768 a.u. while that of $\mathbf{5}^{-} \mathrm{H}^{+}$(a proton is added at the $\mathrm{O}$ atom of 5) and $\mathrm{H}_{2} \mathrm{O}$ is -398.036026 a.u., which would be a reason why we could not find the TS between 3 and 5 .

The energies of addition and elimination of a proton are always problematic in this type calculation because the formation of a proton is not considered. The addition of a proton always gives huge stabilization energy, while the elimination of a proton gives huge destabilization energy. We consider the effects of a proton not to be serious throughout this study. The largest barrier height is $49.3 \mathrm{kcal} / \mathrm{mol}$ and corresponds to the reaction from 4 to 5 that is an elimination of an $\mathrm{H}_{2} \mathrm{O}$ molecule. The second largest barrier height is $42.1 \mathrm{kcal} / \mathrm{mol}$ and corresponds to the reaction from 7 to 8 that is an elimination of a $\mathrm{H}_{2} \mathrm{O}$ molecule. The third largest barrier height is $38.4 \mathrm{kcal} / \mathrm{mol}$ and corresponds to the reaction from 5 to 6 that is an addition of a formaldehyde molecule.

Figure 5 and 6 show the same energy diagrams at the HF/6-31G(d,p) up to the 
formation of compound 9 and MP2/6-31G(d, p) levels up to the formation of compound 8. The three highest barrier heights are $58.5 \mathrm{kcal} / \mathrm{mol}, 52.6 \mathrm{kcal} / \mathrm{mol}$, and $43.6 \mathrm{kcal} / \mathrm{mol}$ at HF/6-31G(d, p) + ZPC level and are $47.7 \mathrm{kcal} / \mathrm{mol}, 38.4 \mathrm{kcal} / \mathrm{mol}$, and $33.1 \mathrm{kcal} / \mathrm{mol}$ at MP2/6-31G(d, p) + ZPC level. Note that the MP2 energies are size-consistent and are not approximate. The view of the structures is almost the same as Fig. 4 and we omit them here.

Figure 7 and 8 show the same energy diagrams introducing the phenyl substituent at $R_{1}$ or $R_{2}$ respectively, at the $H F / 6-31 G(d, p)$ up to the formation of compound 9 . The three largest barrier heights are $59.2 \mathrm{kcal} / \mathrm{mol}, 55.7 \mathrm{kcal} / \mathrm{mol}$, and $43.4 \mathrm{kcal} / \mathrm{mol}$ at HF/6-31G(d,p)+ZPC level for Fig.7 and are $54.3 \mathrm{kcal} / \mathrm{mol}, 53.5 \mathrm{kcal} / \mathrm{mol}$, and 45.1 $\mathrm{kcal} / \mathrm{mol}$ at $\mathrm{HF} / 6-31 \mathrm{G}(\mathrm{d}, \mathrm{p})+\mathrm{ZPC}$ level for Fig.8. The view of the structures is also omitted here. It is very interesting that the largest barrier height of Fig.7 is larger than that of Fig. 8 as the compound in Fig.7 is real one but that of Fig. 8 is not. The activation energy for an addition of a formaldehyde molecule of Fig. 8 is slightly larger than that of Fig.7, and this would be a reason why 2,6-dibenzoyl-1,4-dihydro-3,5-dimethylpyridine is not obtained as a product.

After all, the rate determining step is a formation of FLUORAL-P molecule. This agrees with the fact that the FLUORAL-P, KD-XA01, and KD-XA-02, is able to use an 
alternative starting material instead of the acetyl acetone molecule avoiding the heating [11].

All these barrier heights mentioned above are very high but these results agreed with the fact that the whole reaction does not proceed in the gas-phase but in the aqueous solution or in the porous glass, i.e., the environment is very important with the reaction. Note that the barrier heights of an elimination of a water molecule would be reduced by a solvent (water molecules or something revealed the environment of porous glass) catalyzed reaction and would be interesting to in the next step of the present study.

\section{Conclusion}

We have studied the reaction path of the formation of 3,5-diacetyl-1,4-dihydrolutidine (DL1), 3,5-dibenzoyl-1,4-dihydro-2,6-dimethylpyridine (DL2), and 2,6-dibenzoyl-1,4-dihydro-3,5-dimethylpyridine with the ab initio molecular orbital method at HF/3-21G and HF/6-31G(d, p) levels. For DL1, we also calculated at MP2/6-31G(d,p) level. Some optimized and transition state structures at HF/6-31G(d,p) and MP2/6-31G(d,p) levels have not been obtained yet. The barrier heights of $\mathrm{H}_{2} \mathrm{O}$ elimination reactions (4 to 5 and 7 to 8 ) are ca. $50-60 \mathrm{kcal} / \mathrm{mol}$ and very high in the gas phase, however, this is well agreed with the experimental results that the reaction 
proceeds in aqueous solutions, not in gas phase. The next step of the present study is an inclusion of the solvent effects. The study is in progress and to be published in elsewhere.

\section{Acknowledgment}

The authors are grateful to Professor Keiji Kobayashi at Josai University and Umpei Nagashima at National Institute of Advanced Industrial Science and Technology (AIST) for stimulating discussions and suggestions.

\section{References and Note}

[1] Formaldehyde, Chemical Week, June 12, 2002, 32-33.

[2] Thorud, S.; Gjolstad, M.; Ellingsen, D. G.; P. Molander, P., J. Environ. Monit., 2005,

$7,586-591$.

[3] Hanoune, B.; LeBris, T.; Allou, L.; Marchand, C.; le Calve, S., Atmos. Environ., 2006,

$40, \quad 5768-5775$.

[4] Weschler, C. J.; Hodgson, A. T.; Wooley, J. D., Environ. Sci.Technol., 1992, 26, $2371-2377$.

[5] Tago, H.; Kimura, H.; Kozawa, K.; Fujie, K., Water Air Soil Pollut. 2005, 163, $269-280$.

[6] http://www.euro.who.int/document/aiq/5 8formaldehyde.pdf. 
[7] Nash, T., Biochem J., 1953, 55, 416-421.

[8] Maruo, Y. Y.; Nakamura, J.; Uchiyama, M., Talanta, 74 (2008) 1141-1147.

[9] Gaussian 09, Revision A.1, Frisch, M. J.; Trucks, G. W.; Schlegel, H. B.; Scuseria, G.

E.; Robb, M. A.; Cheeseman, J. R.; Scalmani, G.; Barone, V.; Mennucci, B.; Petersson, G.

A.; Nakatsuji, H.; Caricato, M.; Li, X.; Hratchian, H. P.; Izmaylov, A. F.; Bloino, J.; Zheng,

G.; Sonnenberg, J. L.; Hada, M.; Ehara, M.; Toyota, K.; Fukuda, R.; Hasegawa, J.;

Ishida, M.; Nakajima, T.; Honda, Y.; Kitao, O.; Nakai, H.; Vreven, T.; Montgomery, Jr., J.

A.; Peralta, J. E.; Ogliaro, F.; Bearpark, M.; Heyd, J. J.; Brothers, E.; Kudin, K. N.;

Staroverov, V. N.; Kobayashi, R.; Normand, J.; Raghavachari, K.; Rendell, A.; Burant, J.

C.; Iyengar, S. S.; Tomasi, J.; Cossi, M.; Rega, N.; Millam, N. J.; Klene, M.; Knox, J. E.;

Cross, J. B.; Bakken, V.; Adamo, C.; Jaramillo, J.; Gomperts, R.; Stratmann, R. E.;

Yazyev, O.; Austin, A. J.; Cammi, R.; Pomelli, C.; Ochterski, J. W.; Martin, R. L.;

Morokuma, K.; Zakrzewski, V. G.; Voth, G. A.; Salvador, P.; Dannenberg, J. J.; Dapprich,

S.; Daniels, A. D.; Farkas, Ö.; Foresman, J. B.; Ortiz, J. V.; Cioslowski, J.; Fox, D. J.

Gaussian, Inc., Wallingford CT, 2009.

[10] Compton, P. J.; Purdy, W. C., Anal. Chim. Acta, 1980, 119, 349-357.

[11] Suzuki, Y.; Nakano, N.; Suzuki, K., Environ. Sci. Technol. 2003, 37, 5695-5700 


\section{Figure Captions}

Figure 1. The reaction formula of the formation of the lutidine derivatives, 3,5-diacetyl-1,4-dihydro-2,6-dimethylpyridine $\left(\mathrm{R}_{1}=\mathrm{R}_{2}=\mathrm{CH}_{3}\right)$, 3,5-dibenzoyl-1,4- dihydro2,6-dimethylpyridine $\quad\left(\mathrm{R}_{1}=\mathrm{Ph}, \quad \mathrm{R}_{2}=\mathrm{CH}_{3}\right), \quad$ and 3,5-dibenzoyl-1,4-dihydro-2,6-diphenylpyridine $\left(\mathrm{R}_{1}=\mathrm{R}_{2}=\mathrm{Ph}\right)$.

Figure 2. Possible reaction path from acetyl acetone to lutidine derivative.

Figure 3. Energy diagram of the reaction starting from pentane-2,4-dione to 3,5-diacetyl-1,4-dihydro-2,6-dimethylpyridine at the HF/3-21G level after the inclusion of the zero point energies correction (ZPC). TS denotes the transition state.

Figure 4. The schematic views of the optimized and the transition state structures corresponding to Fig. 3 .

Figure 5. Energy diagram of the reaction starting from pentane-2,4-dione to 3,5-diacetyl-1,4-dihydro-2,6-dimethylpyridine at the $\mathrm{HF} / 6-31 \mathrm{G}(\mathrm{d}, \mathrm{p})$ level after the inclusion of the zero point energies correction (ZPC). TS denotes the transition state.

Figure 6. Energy diagram of the reaction starting from pentane-2,4-dione to 3,5-diacetyl-1,4-dihydro-2,6-dimethylpyridine at the MP2/6-31G(d, p) level after the inclusion of the zero point energies correction (ZPC). TS denotes the transition state. 
Figure 7. Energy diagram of the reaction starting from 1-phenyl-1,3-butanedione to 3,5-dibenzoyl-1,4-dihydro-2,6-dimethylpyridine at the HF/6-31G(d,p) level after the inclusion of the zero point energies correction (ZPC). TS denotes the transition state.

Figure 8. Energy diagram of the reaction starting from 1-phenyl-1,3-butanedione to 2,6-dibenzoyl-1,4-dihydro-3,5-dimethylpyridine at the $\mathrm{HF} / 6-31 \mathrm{G}(\mathrm{d}, \mathrm{p})$ level after the inclusion of the zero point energies correction (ZPC). TS denotes the transition state. 


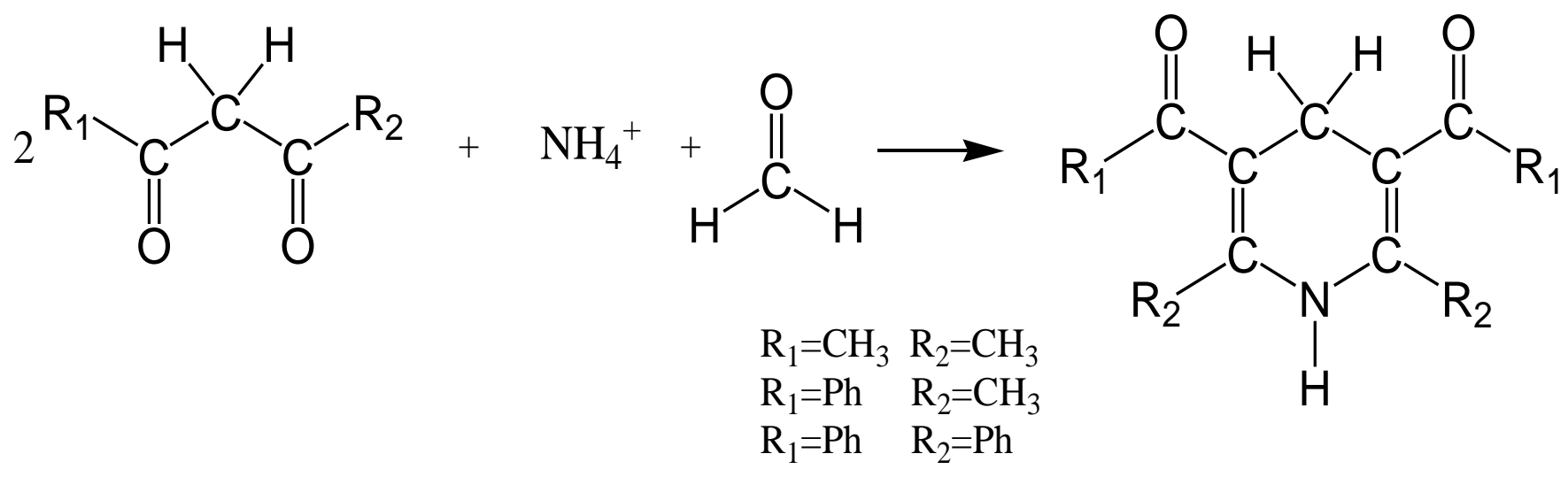

Figure 1 Teramae and Maruo 

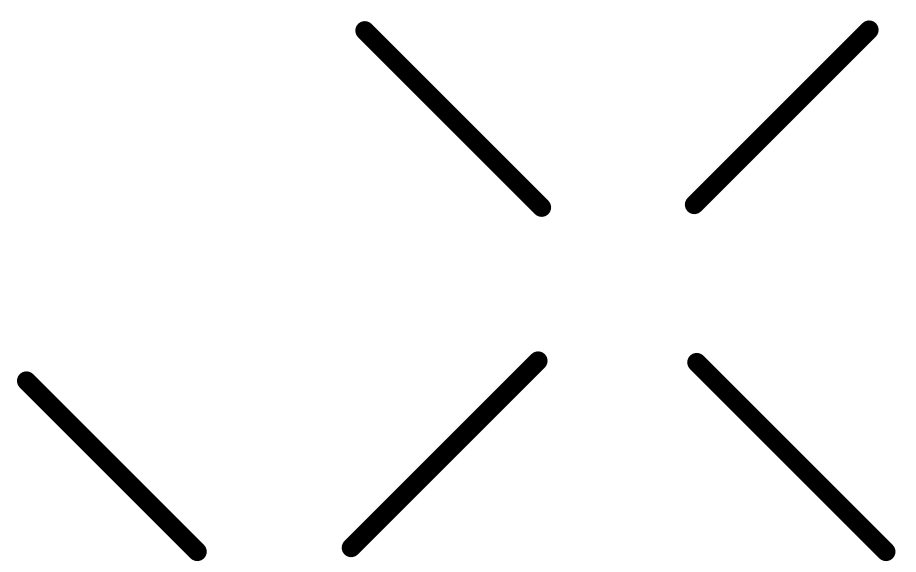

॥

Figure 2 Teramae and Maruo 

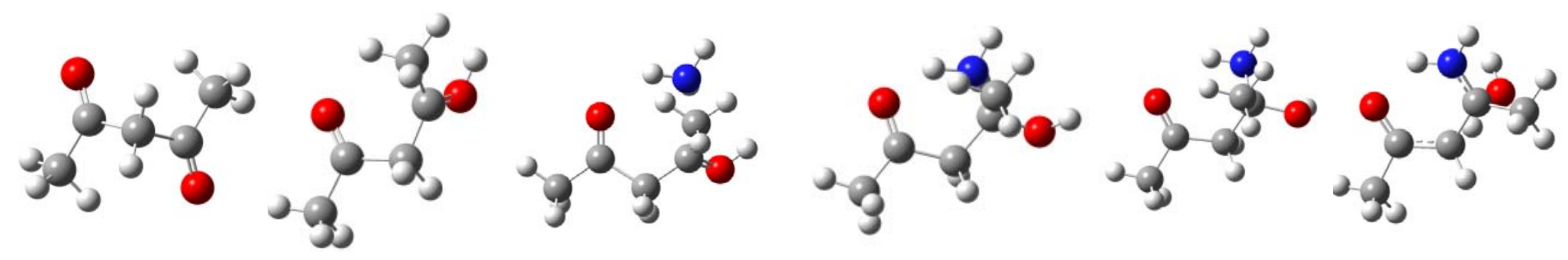

1

2

TS

3

4

TS
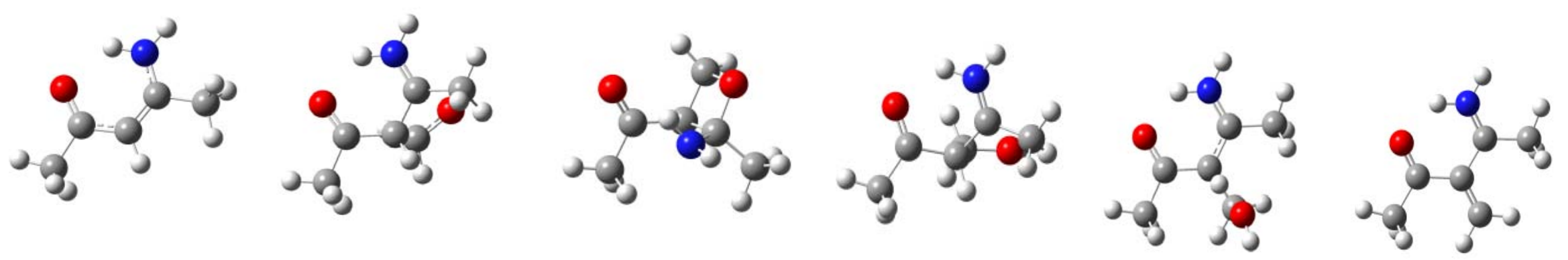

FLUORAL-P

5

TS

6

7

TS

8

के के

TS

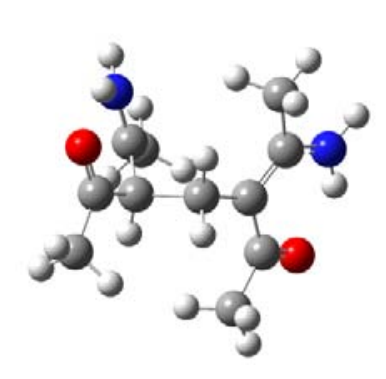

9

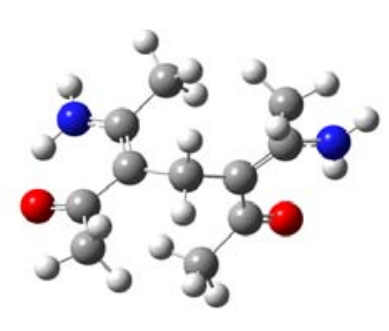

10

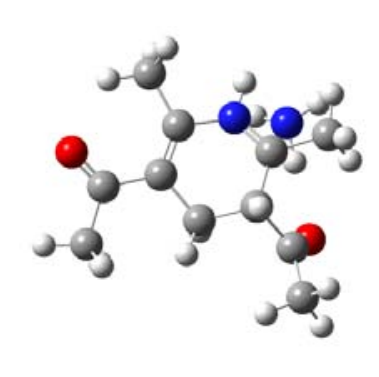

TS

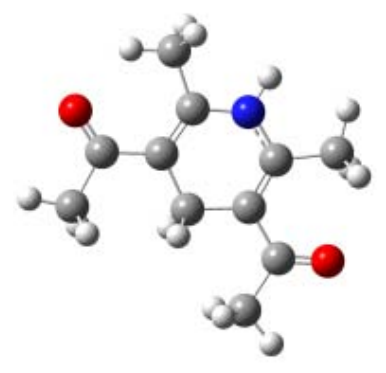

11

Figure 4 Teramae and Maruo 


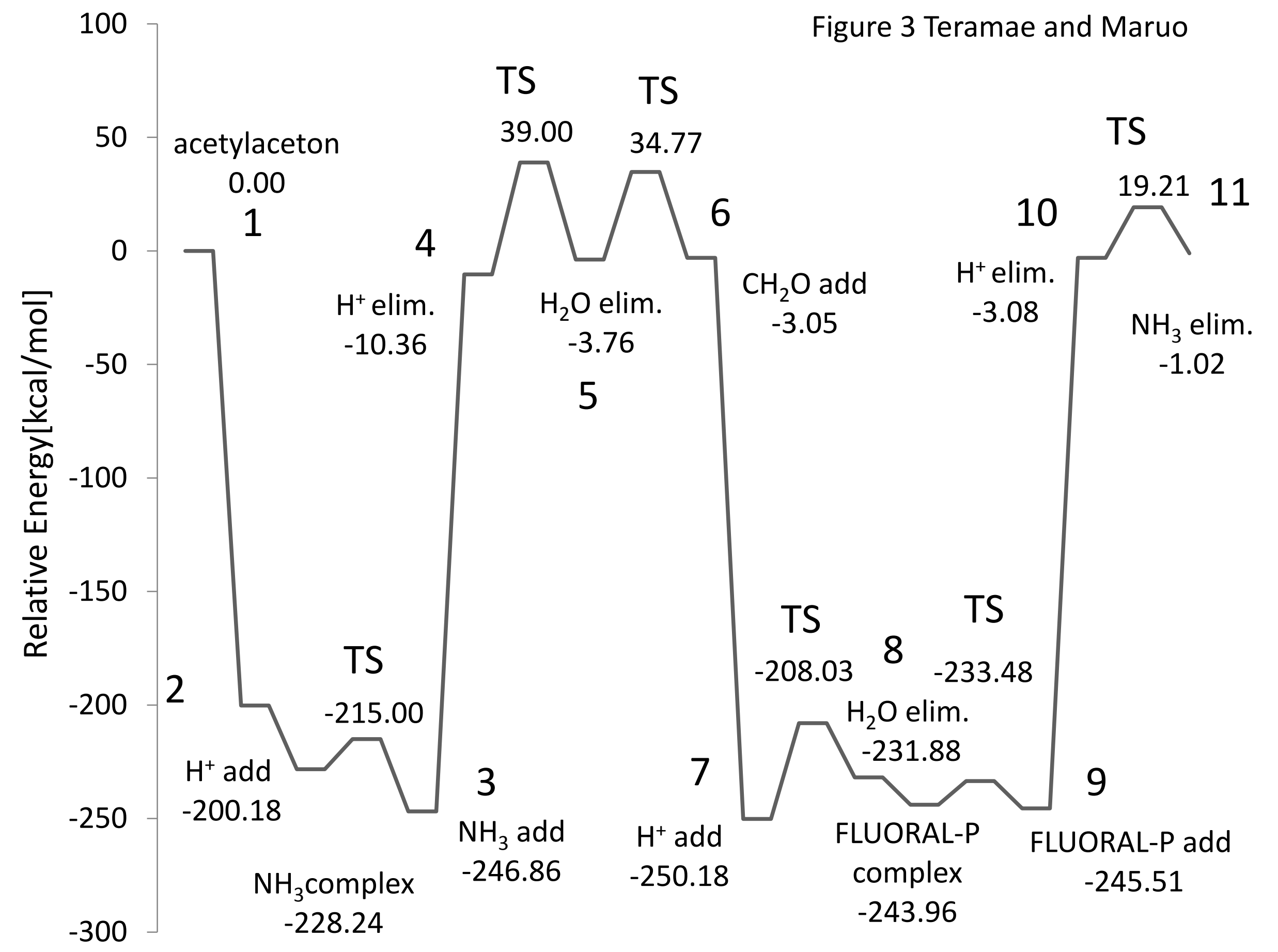




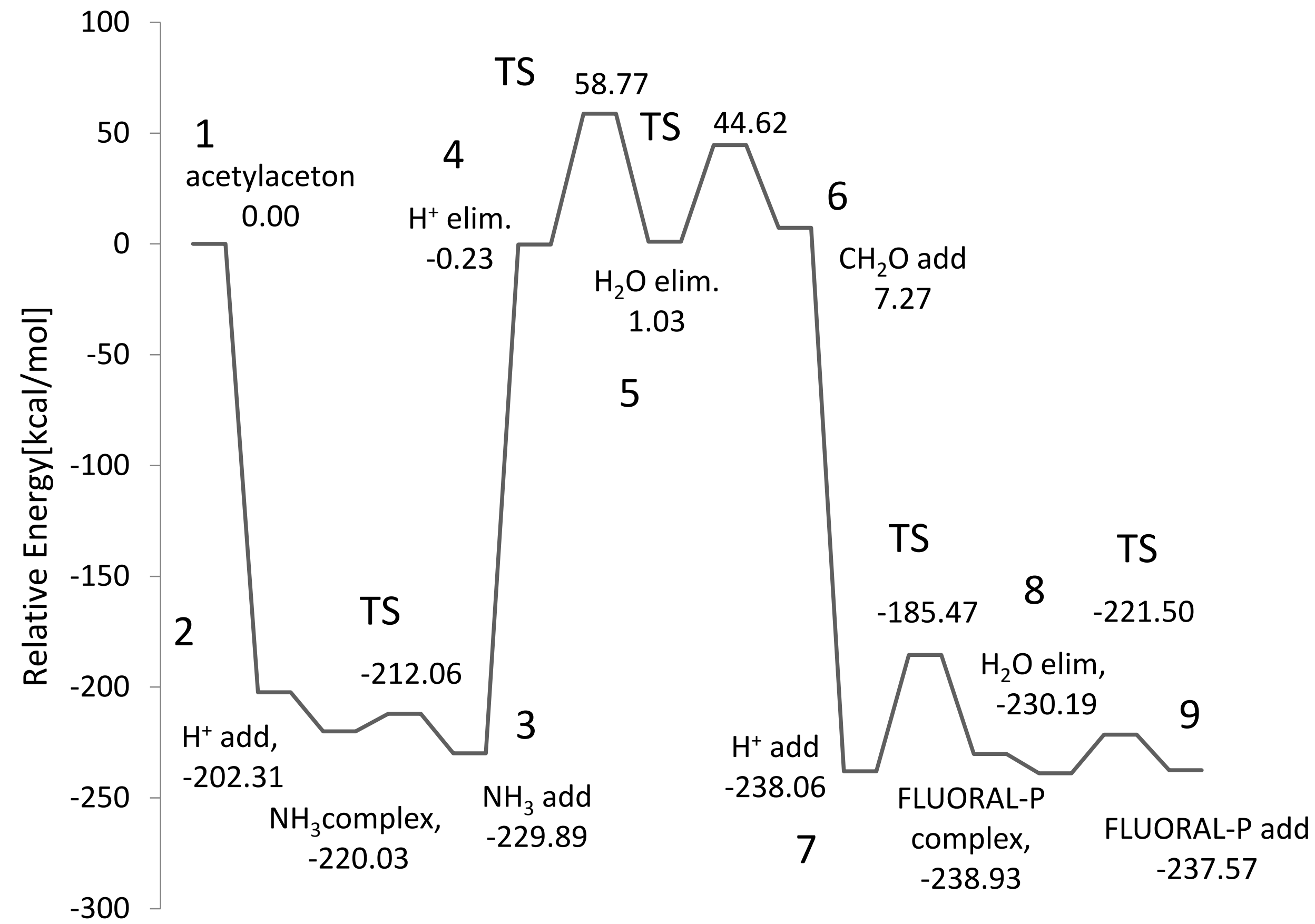

Figure 5 Teramae and Maruo 


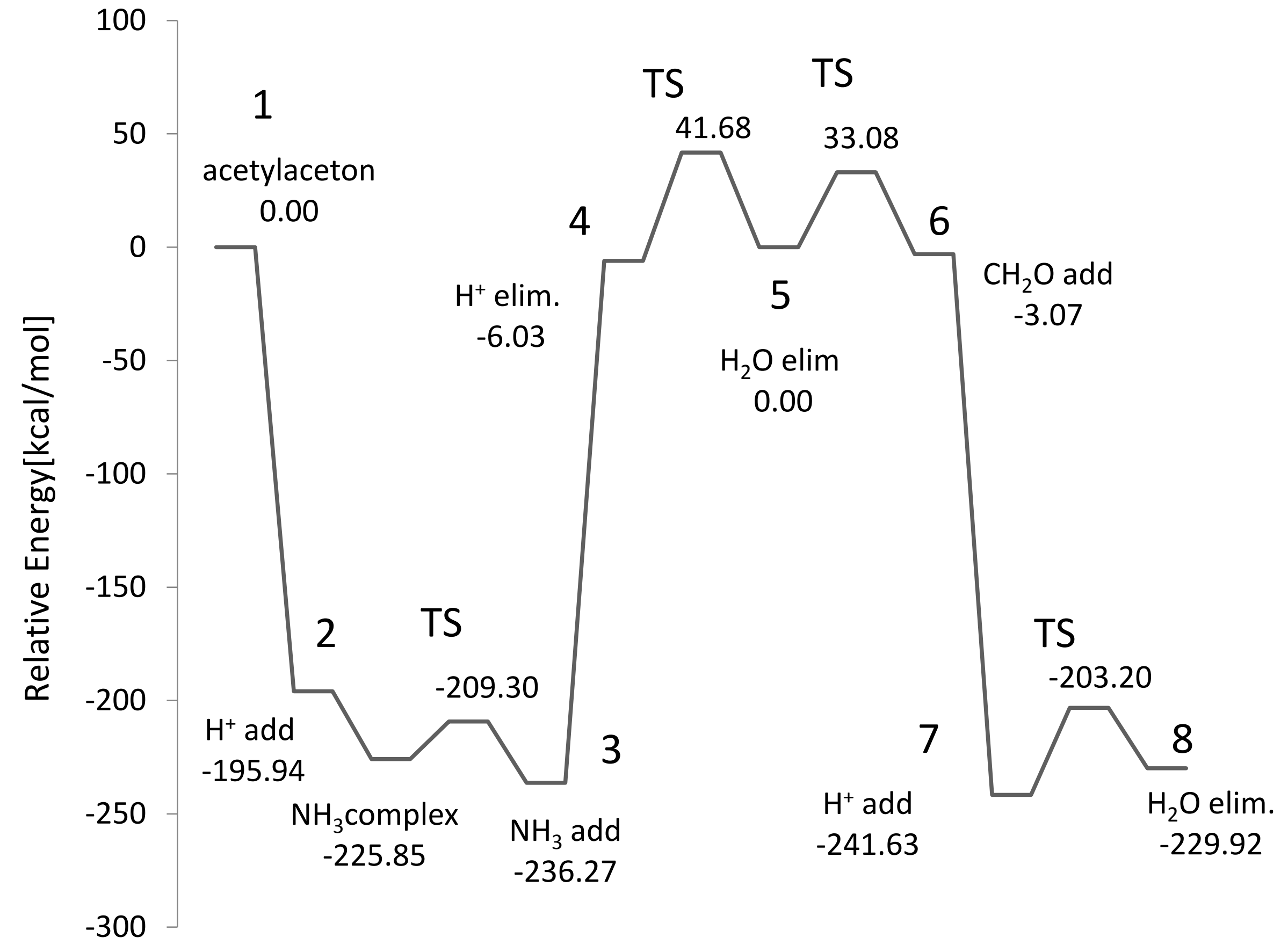

Figure 6 Teramae and Maruo 


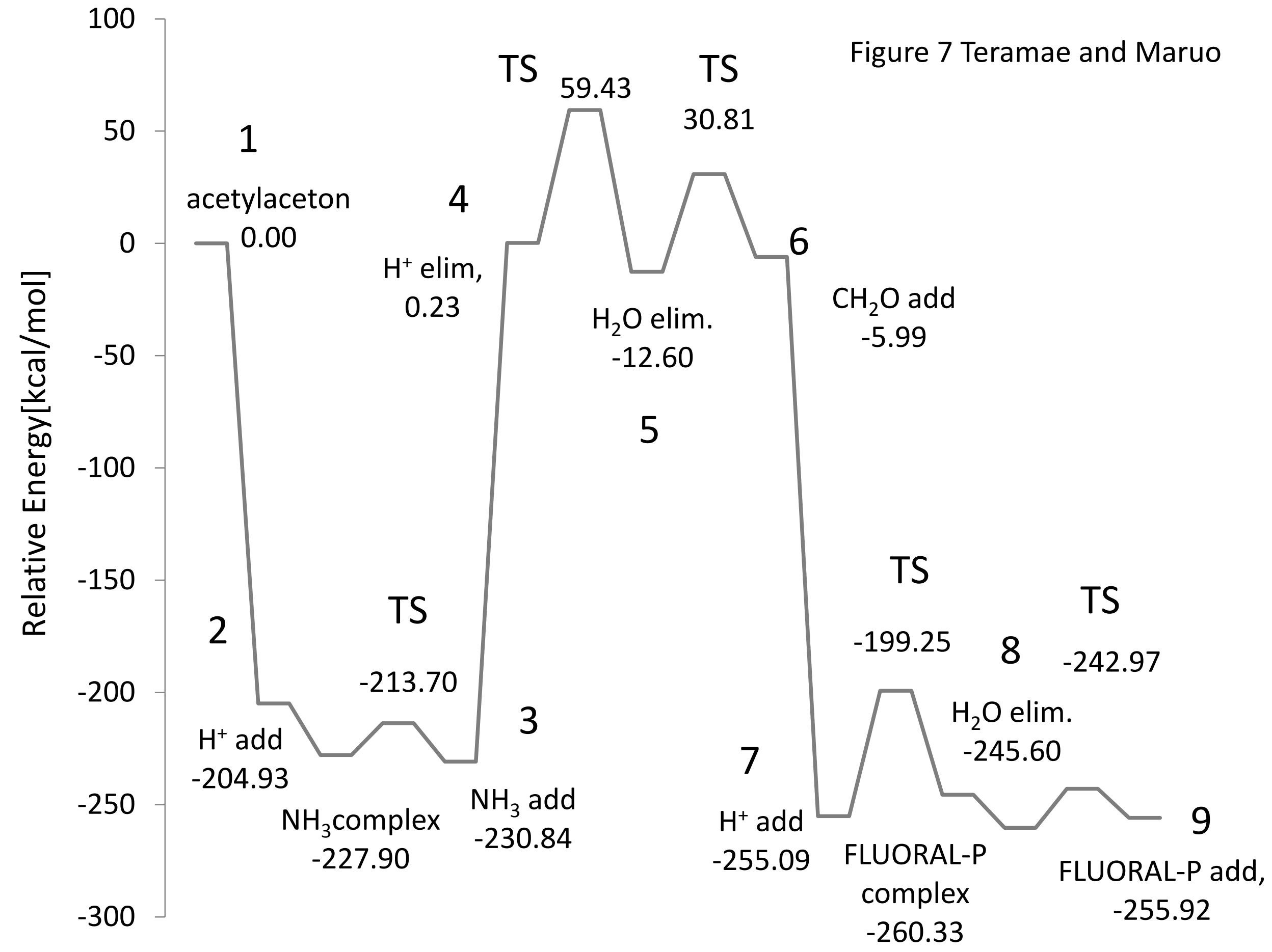


